\title{
Neurodegenerative proteinopathies associated with neuroinfections
}

\author{
Krisztina Danics ${ }^{1,2} \cdot$ Shelley L. Forrest ${ }^{3,4} \cdot$ Istvan Kapas $^{5} \cdot$ Irene Erber $^{6} \cdot$ Susanne Schmid ${ }^{6} \cdot$ Klára Törö $^{1}$. \\ Katalin Majtenyi ${ }^{2} \cdot$ Gabor G. Kovacs ${ }^{7,8}$
}

Received: 12 June 2021 / Accepted: 20 June 2021 / Published online: 5 July 2021

(C) The Author(s), under exclusive licence to Springer-Verlag GmbH Austria, part of Springer Nature 2021

\begin{abstract}
Infectious agents, including viruses and bacteria, are proposed to be involved in the pathogenesis of Alzheimer's disease (AD). According to this hypothesis, these agents have capacity to evade the host immune system leading to chronic infection, inflammation, and subsequent deposition of $\mathrm{A} \beta$ and phosphorylated-tau in the brain. Co-existing proteinopathies and agerelated pathologies are common in $\mathrm{AD}$ and the brains of elderly individuals, but whether these are also related to neuroinfections remain to be established. This study determined the prevalence and distribution of neurodegenerative proteinopathies in patients with infection-induced acute or chronic inflammation associated with herpes simplex virus (HSV) encephalitis $(n=13)$ and neurosyphilis $(n=23)$. The mean age at death in HSV patients was $53 \pm 12$ years (range 24-65 years) and survival was 9 days -6 years following initial infection. The mean age at death and survival in neurosyphilis patients was $60 \pm 15$ years (range 36-86 years) and 1-5 years, respectively. Neuronal tau-immunoreactivity and neurites were observed in 8 HSV patients and 19 neurosyphilis patients, and in approximately half of these, this was found in regions associated with inflammation and expanding beyond regions expected from the Braak stage of neurofibrillary degeneration. Five neurosyphilis patients had cortical ageing-related tau astrogliopathy. A $\beta$-plaques were found in 4 HSV patients and 11 neurosyphilis patients. Lewy bodies were observed in one HSV patient and two neurosyphilis patients. TDP-43 pathology was absent. These observations provide insights into deposition of neurodegenerative proteins in neuroinfections, which might have implications for COVID-19 patients with chronic and/or post-infectious neurological symptoms and encephalitis.
\end{abstract}

Keywords Alzheimer's disease $\cdot$ Herpes simplex virus $\cdot$ Neuro-infection $\cdot$ Neurosyphilis $\cdot$ Proteinopathy $\cdot$ Tau

Krisztina Danics and Shelley L. Forrest contributed equally.

Previous address for GGK: Affiliations 2 and 6.

Gabor G. Kovacs

gabor.kovacs@uhnresearch.ca

1 Department of Forensic and Insurance Medicine, Semmelweis University, Budapest, Hungary

2 Neuropathology and Prion Disease Reference Center, Department of Forensic and Insurance Medicine, Semmelweis University, Budapest, Hungary

3 Dementia Research Centre, School of Biomedical Sciences, Faculty of Medicine, Health and Human Sciences, Macquarie University, Sydney, Australia

4 Faculty of Medicine and Health, School of Medical Sciences, University of Sydney, Sydney, Australia

\section{Introduction}

Neurodegenerative disorders are a clinically, pathologically and genetically diverse group of disorders characterised by progressive deterioration of neurons and/or glia, their synapses, and network connections. The clinical phenotype of

5 Department of Neurology, St. Janos Hospital, Budapest, Hungary

6 Division of Neuropathology and Neurochemistry, Department of Neurology, Medical University of Vienna, Vienna, Austria

7 Tanz Centre for Research in Neurodegenerative Disease and Department of Laboratory Medicine and Pathobiology, University of Toronto, Krembil Discovery Tower, 60 Leonard Ave, Toronto, ON M5T 0S8, Canada

8 Laboratory Medicine Program \& Krembil Brain Institute, University Health Network, Toronto, ON, Canada 
these disorders is related to the severity and regional distribution of neuronal loss (Mrdjen et al. 2019; Forrest et al. 2019a). Importantly, disease-specific protein aggregates in neurons and/or glia occur or deposit in extracellular locations in vulnerable brain regions, which form the molecular classification of neurodegenerative disorders. In addition, co-existing neurodegenerative proteinopathies and agerelated pathologies are increasingly recognised (Kovacs 2019), and how these relate and interact with the clinical phenotype, neuropathological changes, and disease pathogenesis are the focus of current research. Another pathology associated with accumulation of tau protein in astrocytes, ageing-related tau astrogliopathy (ARTAG), is commonly found in the brains of elderly individuals and in patients with neurodegenerative disorders (Kovacs et al. 2016). It is characterised by thorn-shaped astrocytes and granular fuzzy astrocytes, with different ARTAG types recognised. Recently, a sequential distribution pattern for the different types of ARTAG has been proposed (Kovacs et al. 2018) and while its clinical relevance is yet to be established, the regional distribution and type of ARTAG vary between neurodegenerative diseases and normal ageing. For example, lobar white matter ARTAG is frequent in Alzheimer's disease (AD), whereas the basal forebrain is a predilection site for ARTAG in the elderly (Kovacs et al. 2018).

Numerous studies have suggested associations between infectious agents, including viruses and bacteria, and sporadic $\mathrm{AD}$, and are suggested to be involved in its pathogenesis. The altered blood-brain barrier in patients with $\mathrm{AD}$ is also likely to predispose these patients to viral and bacterial infections. These agents are capable of evading the immune system, leading to chronic infection, inflammation and subsequent deposition of $A \beta$ and abnormal tau phosphorylation in the brain. Herpes simplex virus (HSV) is a neurotrophic virus belonging to the Herpesviridae family, which has many species including HSV-1 and 2, which infects mucosal epithelia and resides in the peripheral nervous system in a latent form, resulting in life-long infection. Reactivation leads to viral replication and acute infection (Harris and Harris 2015; Sait et al. 2021). Occasionally, HSV-1 spreads to the CNS and is the most common cause of viral encephalitis. PCR studies have detected latent HSV-1 in $70-100 \%$ of sporadic AD and people $>65$ years of age (Jamieson et al. 1991; Looker et al. 2015). The presence of HSV-1 has been reported in predilection brain regions of AD pathology, including the temporal cortex and hippocampus, and a higher proportion of HSV-1 DNA is associated with $\mathrm{A} \beta$ plaques in $\mathrm{AD}$ patients compared with elderly controls (Laval and Enquist 2021; Harris and Harris 2015). Anti-HSV-1 IgM antibody titres have been correlated with plasma levels of $A \beta_{1-40}$ and $A \beta_{1-42}$ isoforms (Féart et al. 2011) and a higher risk of developing AD (Letenneur et al. 2008), suggesting that HSV-1 reactivation or recent infection is involved in the pathogenesis of $\mathrm{AD}$ leading to the accumulation of $A \beta$ plaques in the brain. In addition, carriers of the apolipoprotein-E $\varepsilon 4$ (APOE $\varepsilon 4$ ) allele have an increased risk of developing $\mathrm{AD}$, and in combination with HSV-1 infection, this risk of developing $\mathrm{AD}$ increases 12-fold (Lin et al. 1995).

Spirochete Treponema pallidum infections causing syphilis have also been associated with the pathogenesis of $\mathrm{AD}$ (Miklossy 2015). Although the incidence of syphilis has been reduced with the development of antibiotics, partial or incomplete antibiotic treatment allows T. pallidum to survive and persist in the CNS (Deckert 2015). Following a latency period of months to years after primary infection and the characteristic ulcerative lesions, persisting spirochetes can cause neurosyphilis that includes different forms, such as asymptomatic neurosyphilis, meningeal and meningovascular neurosyphilis, general paresis, and tabes dorsalis. The outer membrane of T. pallidum lacks lipopolysaccharide, the inflammatory glycolipid found in Gram-negative bacteria, and has a low density of integral membrane proteins, which allow the bacteria to evade the immune system, cause inflammation and chronic CNS infection (Radolf et al. 2016). CNS involvement can occur at any stage of infection and neuropathological examination is characterised by inflammation of the meninges and leptomeningeal vessels, and gummas, round lesions with necrotic centres (Deckert 2015). Spirochetal colonies are typically restricted to the cerebral cortex, cortical and leptomeningeal vessels, and have a similar morphology to neuritic plaques (Miklossy 2015). Studies have also demonstrated spirochetal-specific antigens and DNA co-localised with A $\beta$ plaques, the presence of multiple $A \beta$ isoforms in spirochetal colonies and in cortical and leptomeningeal vessel walls exhibiting $A \beta$ deposits (Miklossy 2015), and an increased risk of AD in patients with T. pallidum infection (Maheshwari and Eslick 2015). To date, systematic analyses have not been performed in human brains to determine the prevalence of $\mathrm{AD}$ pathology and other neurodegenerative proteinopathies in patients with neuroinfections. To address this, we investigated the prevalence and distribution of neurodegenerative proteinopathies in patients with infection-induced acute or chronic inflammation associated with HSV encephalitis and neurosyphilis, respectively.

\section{Materials and methods}

\section{Case selection and collection of clinical data}

Thirteen cases ( 7 male) with the clinical diagnosis of HSV encephalitis (years of death: 1965-2006) and 23 cases (15 male) with the clinical diagnosis of neurosyphilis (years of death: 1955-1991), paralysis progressive or tabes dorsalis 
with CSF examination indicative of chronic inflammation and positive Wassermann test were selected from the archives of the Neuropathological Laboratory of the Hungarian National Institute of Psychiatry and Neurology. This Institute was closed in 2007 and the archives moved to the Neuropathology and Prion Disease Reference Center, Department of Forensic and Insurance Medicine, Semmelweis University, Budapest, Hungary. Demographic and clinical data were collated from the clinical files retrospectively. This study was approved by the Regional and Institutional Committee of Science and Research Ethics (Nr. 34/2016), Semmelweis University.

\section{Neuropathological assessment}

While all cases had a routine neuropathological assessment throughout the collection period (1955-2006), cases were reviewed by three researchers (KD, SLK and GGK) to identify neurodegenerative pathologies based on current classification criteria. Larger hemispheric anatomical regions were reprocessed for the purposes of the present immunohistochemical examinations. Selection of brain regions examined in each cohort is summarised in Supplementary 1 and was based on neuropathological consensus recommendations for identifying $\mathrm{AD}$ neuropathological change (Montine et al. 2012), including Thal A $\beta$ plaque phase (Thal et al. 2002) and Braak neurofibrillary tangle stage (Braak and Braak 1991), Braak Lewy body stage (Braak et al. 2003), and ARTAG (Kovacs et al. 2016). Brain regions included the cortex (frontal, temporal, parietal and occipital), medial temporal lobe (hippocampus and amygdala), basal ganglia, thalamus and hypothalamus, brainstem (midbrain, pons, medulla oblongata) and cerebellum. Formalin-fixed paraffin-embedded $7 \mu \mathrm{m}$ sections were stained for haematoxylin and eosin, and immunostained at the Institute of Neurology, Medical University of Vienna, with phosphorylated-tau (AT8, 1:200; phospho-epitope Ser202/Thr205; Pierce Biotechnology, Rockford, IL), A $\beta$ (1:50, clone 6F/3D, Dako, Glostrup, Denmark), alpha-synuclein (monoclonal; 1:2,000, clone 5G4, Roboscreen, Leipzig, Germany), phosphorylatedTDP-43 (pTDP-43, phospho-epitope S409/410, 1:2,000, Cosmo Bio, Tokyo, Japan), p62 (monoclonal; 1:1000, BD Transduction, Lexington, KY, USA), glial fibrillary acidic protein (GFAP, polyclonal, 1:3000, Dako, Glostrup, Denmark), and HLA-DR (monoclonal, clone CR3/43; 1:100; Dako, Glostrup, Denmark). In addition, cases with HSV encephalitis were also immunostained for anti-HSV-1 and HSV-2 (polyclonal; 1:2000 and 1:1000, respectively, Dako, Glostrup, Denmark). The DAKO EnVision detection kit, peroxidase and/or DAB (3,3-diaminobenzidine) were used for visualisation of antibody reactions.

\section{Statistical analysis}

Data are presented as the mean \pm standard deviation and the range where specified.

\section{Results}

\section{Clinical and demographic data}

The demographic details and clinical features of patients with HSV encephalitis and neurosyphilis are summarised in Tables 1 and 2, respectively. The mean age at death in patients with HSV encephalitis ( $n=13,7$ male) was $53 \pm 12$ years (range 24-65 years). Survival following HSV encephalitis infection ranged from 9 days to 6 years. Six patients had a very acute infection and short survival of 9-45 days, and five patients survived 7 months -6 years following infection. Survival was unknown in two HSV encephalitis patients. The mean age at death and duration of symptoms in patients with neurosyphilis $(n=23,15$ male) was $60 \pm 15$ years (range $36-86$ years) and $3 \pm 1$ years (range $1-5$ years), respectively.

\section{Overview of histopathological changes}

\section{Herpes simplex virus encephalitis}

Cases with the clinical diagnosis of HSV encephalitis showed macroscopic evidence for micro-hemorrhagic lesions or cystic atrophy in individuals with longer survival ( $\geq 7$ months) (Fig. 1A, B). Microscopic examination revealed variable degree of microhemorrhages (Fig. 1C), microglial nodules (Fig. 1D), perivascular lymphocytic infiltration (Fig. 1E), necrotic lesions (Fig. 1F). Immunostaining for HSV antigens (Fig. 1G-N) showed unequivocal neuronal- and glial cytoplasmic and nuclear immunoreactivity in nine cases, equivocal immunoreactivity in occasional glial cell nuclei in three cases, and in one case, immunoreactivity was not detected. Histopathological changes of cases with HSV encephalitis are summarised in Table 3.

\section{Neurosyphilis}

Cases with the clinical diagnosis of neurosyphilis were characterised by prominent leptomeningeal (Fig. 2A, B) and parenchymal (Fig. 2C, D) inflammation in all regions examined. Cortical regions showed thickening of the meninges and massive inflammatory infiltrate (Fig. 2B). Severe gliosis was observed in cortical grey matter and the underlying white matter was gliotic with vacuolation. Occasional cortical extrusions (Fig. 2A, $\mathrm{M})$ were observed, which contained neurons. Grey and 
Table 1 Summary of demographic and clinical features in patients with herpes simplex virus encephalitis

\begin{tabular}{|c|c|c|c|c|c|c|c|c|c|c|c|c|c|}
\hline & \multicolumn{13}{|c|}{ Case no } \\
\hline & 1 & 2 & 3 & 4 & 5 & 6 & 7 & 8 & 9 & 10 & 11 & 12 & 13 \\
\hline Gender & $\mathrm{F}$ & $\mathrm{F}$ & M & $\mathrm{F}$ & M & M & $\mathrm{F}$ & $\mathrm{F}$ & $\mathrm{M}$ & $\mathrm{F}$ & M & M & M \\
\hline Age at death $(y)$ & 55 & 56 & 42 & 66 & 58 & 63 & 58 & 51 & 65 & 24 & 65 & 41 & 49 \\
\hline Disease duration & $9 \mathrm{~d}$ & $11 \mathrm{~d}$ & $12 \mathrm{~d}$ & $16 \mathrm{~d}$ & $23 \mathrm{~d}$ & $45 \mathrm{~d}$ & $7 \mathrm{~m}$ & $1 \mathrm{y}$ & $2 y$ & $3 y$ & $6 y$ & na & na \\
\hline \multicolumn{14}{|l|}{ Behavioural features } \\
\hline \multicolumn{14}{|c|}{ Behavioural disorder } \\
\hline Personality change & & & & & & & & & $\mathrm{x}$ & & $\mathrm{x}$ & & \\
\hline \multicolumn{14}{|l|}{ Executive deficits } \\
\hline Restlessness & & & $\mathrm{x}$ & & & $\mathrm{x}$ & & & & $\mathrm{x}$ & & & \\
\hline \multicolumn{14}{|l|}{ Language features } \\
\hline Aphasia & & & & & & $\mathrm{x}$ & & $\mathrm{x}$ & & & $\mathrm{x}$ & & \\
\hline Dysarthria & & & $\mathrm{x}$ & & & & & $\mathrm{x}$ & & & $\mathrm{x}$ & & \\
\hline \multicolumn{14}{|l|}{ Motor features } \\
\hline Parkinsonism & & & & & & & & & & & & & $\mathrm{x}$ \\
\hline Tremor & $\mathrm{x}$ & & $\mathrm{x}$ & & & & & $\mathrm{x}$ & & & & & \\
\hline \multicolumn{14}{|l|}{ Pyramidal signs } \\
\hline Gait disturbance & & & & & & $\mathrm{x}$ & & & & & $\mathrm{x}$ & & \\
\hline Ataxia & & & & & & & & $\mathrm{x}$ & $\mathrm{x}$ & & $\mathrm{x}$ & & \\
\hline Facial paralysis & $\mathrm{x}$ & & & & & & & $\mathrm{x}$ & & $\mathrm{x}$ & & & \\
\hline Hyperreflexia & $\mathrm{x}$ & & & & & & & & & $\mathrm{x}$ & & & \\
\hline Hyporeflexia & & & & $\mathrm{x}$ & $\mathrm{x}$ & & & & & & & & \\
\hline \multicolumn{14}{|l|}{ Myoclonus } \\
\hline Primitive reflexes & & & & & & & $\mathrm{x}$ & $\mathrm{x}$ & & $\mathrm{x}$ & & & \\
\hline Hemiparesis & $\mathrm{x}$ & $\mathrm{x}$ & & & & & & & $\mathrm{x}$ & $\mathrm{x}$ & & & \\
\hline \multicolumn{14}{|l|}{ Pupillary areflexia } \\
\hline \multicolumn{14}{|c|}{ Neuropsychiatric features } \\
\hline Hallucinations & $\mathrm{x}$ & & $\mathrm{x}$ & & & & & & & & & & \\
\hline \multicolumn{14}{|l|}{ Depression } \\
\hline \multicolumn{14}{|l|}{ Paranoia } \\
\hline \multicolumn{14}{|l|}{ Autonomic features } \\
\hline Dizziness & & & & & & $\mathrm{x}$ & & $\mathrm{x}$ & & & & & \\
\hline \multicolumn{14}{|l|}{ Sensory features } \\
\hline \multicolumn{14}{|l|}{ Paraesthesia } \\
\hline \multicolumn{14}{|l|}{ Sensory neuropathy } \\
\hline \multicolumn{14}{|l|}{ Other features } \\
\hline Dementia & & & & & & $\mathrm{x}$ & $\mathrm{x}$ & & & & $\mathrm{x}$ & & \\
\hline Deterioration & & & $\mathrm{x}$ & & & $\mathrm{x}$ & $\mathrm{x}$ & $\mathrm{x}$ & & & & & \\
\hline \multicolumn{14}{|l|}{ Hypacusis } \\
\hline Convulsions & & $\mathrm{x}$ & & & & & & $\mathrm{x}$ & $\mathrm{x}$ & $\mathrm{x}$ & & & \\
\hline \multicolumn{14}{|l|}{ Anisocoria } \\
\hline Delirium tremens & $\mathrm{x}$ & & $\mathrm{x}$ & $\mathrm{x}$ & $\mathrm{x}$ & & & & & & & & \\
\hline Alcoholism & $\mathrm{x}$ & & $\mathrm{x}$ & & $\mathrm{x}$ & & & & & & & & \\
\hline Incontinence & & & & & & & $\mathrm{x}$ & $\mathrm{x}$ & & & & & \\
\hline
\end{tabular}

$d$ days, $m$ months, $y$ years, $n a$ not available, $F$ female, $M$ male white matter perivascular inflammation (Fig. 2E-H) was observed in most regions examined and many arterioles had thickened walls and a few showed amyloid angiopathy (Fig. 2E). Numerous cortical and subcortical infarcts with frank tissue disruption and lymphocytic nodules
(Fig. 2I, J), reactive gemistocytic astrocytes (Fig. 2K) and macrophages (Fig. 2L) were observed in various locations in the examined brains. 
Neurodegenerative proteinopathies associated with neuroinfections

1555

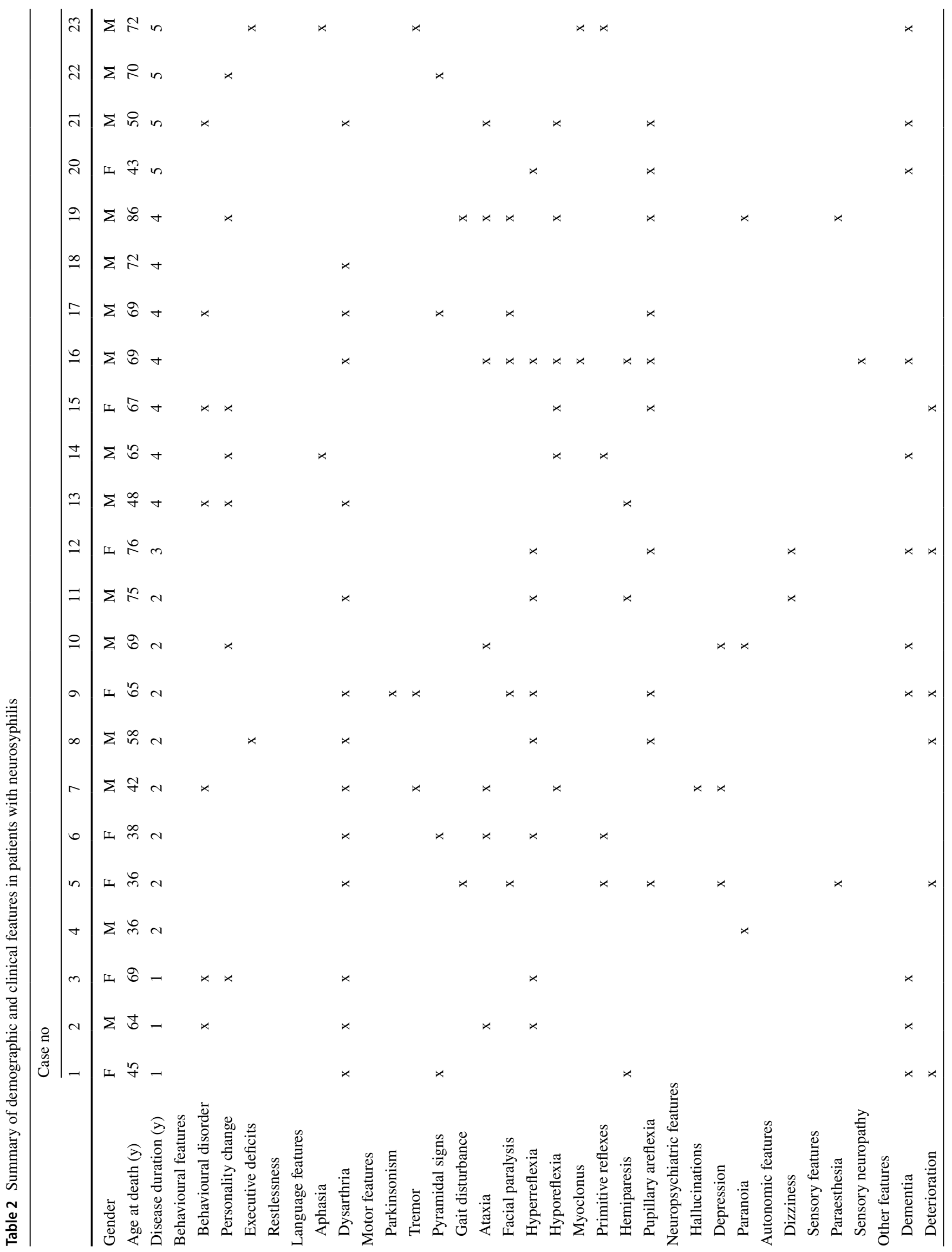

Springer 


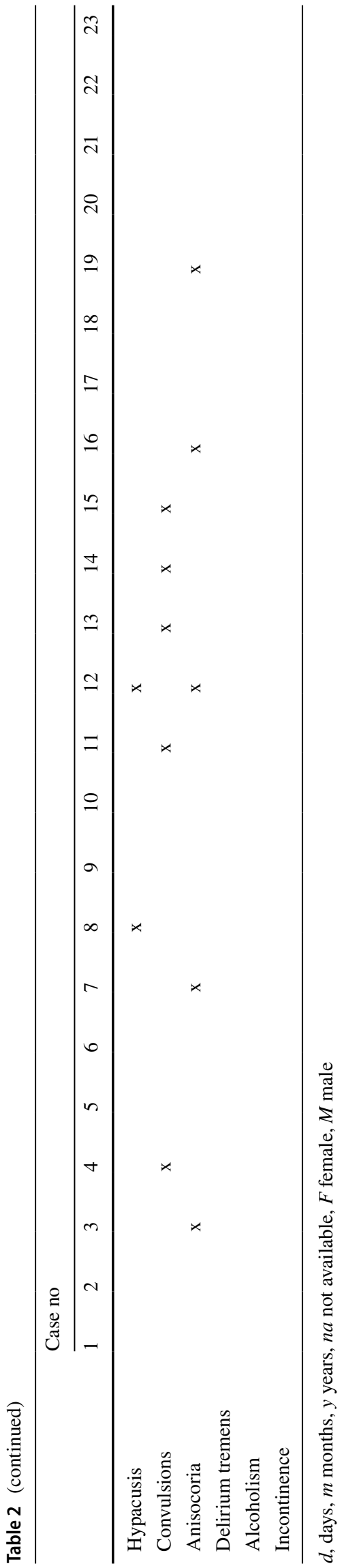

\section{Immunostaining for AT8}

\section{Herpes simplex virus encephalitis}

Neuropathological features are summarised in Table 4 . Neuronal AT8 immunoreactivity and neuropil threads were found in 8 out of the 13 cases with HSV encephalitis (Fig. 3A-H). Three cases had Braak NFT stage I, one case Braak stage 1a (brainstem), one case each contained Braak NFT stages II and III, and Braak stage could not be determined in one case. In three cases, AT8 immunoreactivity was also found in regions associated with inflammation (Fig. 3C-H), including the substantia nigra (Fig. 3C, D). In one case (Case \#12, disease duration not known), few AT8immunopositive neurons and neurites were observed in the substantia nigra and tegmentum with perivascular inflammation. In the second case (Case 4, disease duration $=16$ days), numerous AT8-immunopositive threads, grains and neurons were observed in regions containing inflammation including the hippocampus, entorhinal cortex, basal ganglia, thalamus and amygdala. This case also contained granular fuzzy astrocytes in the thalamus only, as seen in gray matter ARTAG. In the third case (Case 1, disease duration $=9$ days), AT8immunopositive neurons and neurites were observed close to inflamed areas in the basal ganglia and midbrain. Two cases showed AT8 immunoreactive neurons in the granule cells of the dentate gyrus associated with severe lesions. Further, tau-immunoreactivities consistent with ARTAG were not observed in any other case with HSV encephalitis.

\section{Neurosyphilis}

Neuropathological features are summarised in Table 5. Neuronal AT8 immunoreactivity and neuropil threads were found in 19 out of 23 cases. In 14 of these cases, AT8 immunoreactivity included regions beyond the regions expected to be involved from their corresponding Braak NFT stage. This comprised AT8-immunopositive neurons and neurofibrillary tangles in the cortex ( 9 cases), basal ganglia ( 1 case, Case \#18) and substantia nigra (1 case, Case \#16), and neuropil threads in the cortex (11 cases), basal ganglia (2 cases), thalamus (1 case) and medulla oblongata ( 2 cases). In 8 cases, AT8-immunopositive neurites and some neurons were also found in regions associated with inflammation. In some cases, clusters of neurites were observed in regions with inflammation. One case had Braak NFT stage VI and a carpet of phosphorylated-tau pathology in all regions examined (Fig. 2S, T) consistent with a high likelihood of AD neuropathological change. Five cases with neurosyphilis had Braak NFT stage I, 6 cases had Braak NFT stage II and 3 cases had Braak NFT stage III. The hippocampus was 


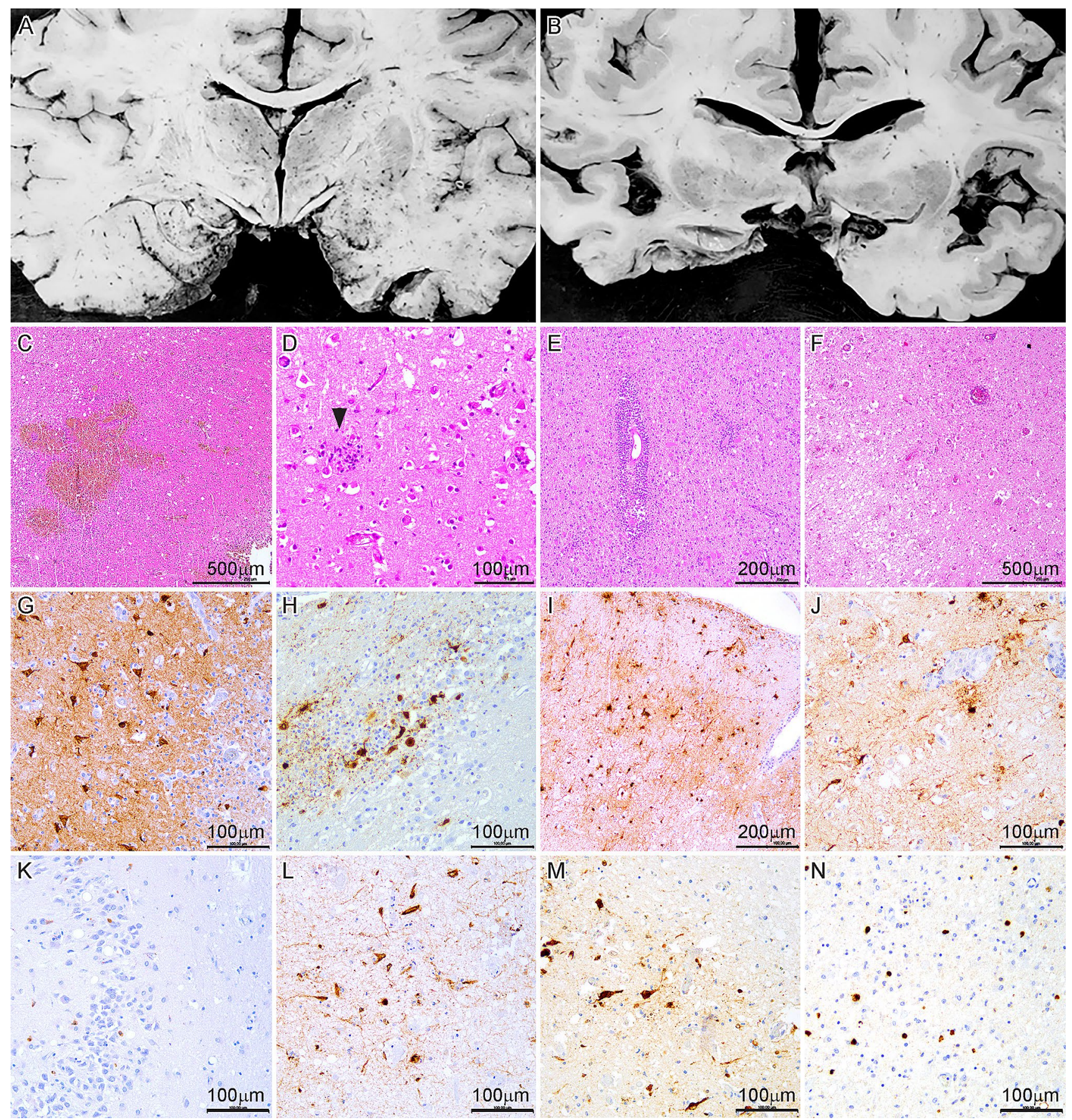

Fig. 1 Representative macroscopic and microscopic neuropathology of the cases with herpes simplex virus encephalitis. Macroscopic archival photos of cases 3 (A) and 11 (B) showing microhemorrhagic lesions (A) and cystic atrophy (B). Microscopic examination reveals variable degree of microhemorrhages $(\mathbf{C})$, microglial nodules (D, arrowhead), perivascular lymphocytic infiltration (E), and necrotic

unavailable in six cases, and Braak NFT stage could not be determined.

Five cases (out of 23) had cortical ARTAG. One case contained subpial and grey matter perivascular ARTAG in lesions (F) in the hippocampus. Immunostaining for HSV-1 (G-N) shows unequivocal neuronal and glial cytoplasmic and nuclear immunoreactivity in the hippocampus $(\mathbf{G}, \mathbf{H}, \mathbf{K}, \mathbf{N})$, temporal cortex $(\mathbf{I}, \mathbf{J}$, $\mathbf{L}, \mathbf{M})$. HSV-1-immunostained sections are counterstained with Haematoxylin

two cortical regions (Fig. 2M-P), characterised by thornshaped astrocytes (Fig. 2Q), which contained inflammation. In this case, subpial ARTAG was also observed in the cortical extrusion areas (Fig. 3M). One case contained 
Table 3 Histopathological changes observation in patients with herpes simplex virus encephalitis and neurosyphilis

\begin{tabular}{|c|c|c|c|c|c|c|c|c|c|}
\hline Case no & Dx & HSV IHC & $\begin{array}{l}\text { Haemorrhagic } \\
\text { necrosis }\end{array}$ & $\begin{array}{l}\text { Non-haemor- } \\
\text { rhagic necrosis }\end{array}$ & $\begin{array}{l}\text { Neutrophil } \\
\text { leukocytes in } \\
\text { tissue }\end{array}$ & $\begin{array}{l}\text { Microglial } \\
\text { nodules }\end{array}$ & $\begin{array}{l}\text { Lymphocytic } \\
\text { infiltrate- } \\
\text { perivascular }\end{array}$ & $\begin{array}{l}\text { Lymphocytic } \\
\text { infiltrate- } \\
\text { parenchyma }\end{array}$ & $\begin{array}{l}\text { Lymphocytic } \\
\text { infiltrate- } \\
\text { meningeal }\end{array}$ \\
\hline 1 & HSV & + & - & $\begin{array}{l}\text { HI, TE, TH, } \\
\text { PO, MO }\end{array}$ & - & $\mathrm{FR}, \mathrm{MB}$ & $\begin{array}{l}\text { HI, TE, FR, } \\
\text { MB, PO, } \\
\text { MO }\end{array}$ & & \\
\hline 2 & HSV & + & HI, TE, MB & $\begin{array}{l}\text { HI, TE, TH, } \\
\text { PO, MO }\end{array}$ & HI, TE & MB & $\begin{array}{l}\text { HI, TE, TH, } \\
\text { PO, MO }\end{array}$ & & \\
\hline 3 & HSV & + & HI, TE & - & - & - & HI, TE & & \\
\hline 4 & $\mathrm{HSV}$ & + & $\mathrm{TE}$ & $\mathrm{TE}$ & - & - & TE, TH, MO & & \\
\hline 5 & HSV & + & - & $\mathrm{HI}$ & - & $\mathrm{HI}$ & $\begin{array}{l}\text { HI, TE, AMY, } \\
\text { TH, BG }\end{array}$ & & \\
\hline 6 & HSV & + & - & - & - & - & PA & & \\
\hline 7 & HSV & $\mathrm{Eq}$ & - & FR, TE & - & $\mathrm{TE}$ & TE, TH, OCC & & \\
\hline 8 & $\mathrm{HSV}$ & + & - & HI, FR, TE & - & HI, TE & HI, TE, FR & & \\
\hline 9 & $\mathrm{HSV}$ & + & - & HI, CBLL, PO & - & - & HI, CBLL, PO & & \\
\hline 10 & HSV & + & - & HI, TE & - & HI, TE & HI, TE & & \\
\hline 11 & HSV & $\mathrm{Eq}$ & - & FR, TE & - & - & HI, FR & & \\
\hline 12 & HSV & - & - & FR, TE & - & FR & $\begin{array}{l}\text { FR, TE, MB, } \\
\text { MO }\end{array}$ & & \\
\hline 13 & HSV & $\mathrm{Eq}$ & - & $\begin{array}{l}\text { FR, TE, TH, } \\
\text { OCC }\end{array}$ & - & - & $\begin{array}{l}\text { FR, TE, OCC, } \\
\text { HI, MB }\end{array}$ & & \\
\hline 1 & NS & & & & & & $\mathrm{Cx}$ & $\mathrm{Cx}, \mathrm{BG}$ & $\mathrm{Cx}$ \\
\hline 2 & NS & & & & & & $\mathrm{Cx}$ & $\mathrm{Cx}$ & $\mathrm{Cx}$ \\
\hline 3 & NS & & & & & & $\mathrm{Cx}$ & Cx. TH & - \\
\hline 4 & NS & & & & & & - & $\mathrm{Cx}, \mathrm{AMY}$ & $\mathrm{Cx}$ \\
\hline 5 & NS & & & & & & - & HI, CBLL & $\mathrm{HI}$ \\
\hline 6 & NS & & & & & & $\mathrm{Cx}$ & $\mathrm{HI}, \mathrm{Cx}, \mathrm{BG}$ & $\mathrm{HI}, \mathrm{Cx}, \mathrm{BG}$ \\
\hline 7 & NS & & & & & & $\mathrm{Cx}, \mathrm{BG}, \mathrm{MO}$ & $\begin{array}{l}\text { HI, Cx, BG, } \\
\text { MO }\end{array}$ & $\begin{array}{l}\text { HI, Cx, BG } \\
\text { HI, Cx, BG }\end{array}$ \\
\hline 8 & NS & & & & & & $\mathrm{HI}$ & $\mathrm{HI}, \mathrm{Cx}, \mathrm{MO}$ & $\mathrm{HI}, \mathrm{Cx}$ \\
\hline 9 & NS & & & & & & - & $\mathrm{HI}$ & $\mathrm{HI}$ \\
\hline 10 & NS & & & & & & - & - & - \\
\hline 11 & NS & & & & & & - & - & - \\
\hline 12 & NS & & & & & & $\mathrm{BG}, \mathrm{MO}$ & $\mathrm{BG}, \mathrm{MO}$ & $\begin{array}{l}\text { BG, MO, } \\
\text { CBLL }\end{array}$ \\
\hline 13 & NS & & & & & & $\mathrm{TH}$ & $\mathrm{TH}$ & - \\
\hline 14 & NS & & & & & & - & - & - \\
\hline 15 & NS & & & & & & - & - & - \\
\hline 16 & NS & & & & & & - & - & - \\
\hline 17 & NS & & & & & & $\mathrm{HI}$ & $\mathrm{HI}$ & $\mathrm{Cx}$ \\
\hline 18 & NS & & & & & & - & - & - \\
\hline 19 & NS & & & & & & - & - & - \\
\hline 20 & NS & & & & & & $\mathrm{Cx}$ & $\mathrm{HI}, \mathrm{Cx}$ & $\mathrm{HI}, \mathrm{Cx}$ \\
\hline 21 & NS & & & & & & - & - & $\mathrm{Cx}$ \\
\hline 22 & NS & & & & & & - & AMY & - \\
\hline 23 & NS & & & & & & - & - & - \\
\hline
\end{tabular}

$A M Y$ amygdala, $B G$ basal ganglia, $C B L L$ cerebellum, $C x$ cortex, $D x$ diagnosis, $E q$ equivocal finding including background staining, $F R$ frontal cortex, $H I$ hippocampus, $H S V$ herpes simplex virus encephalitis, $M B$ midbrain, $M O$ medulla oblongata, $N S$ neurosyphilis, $O C C$ occipital cortex, $P A$ parietal cortex, $P O$ pons, $T E$ temporal cortex, $T H$, thalamus 
occasional grey matter granular fuzzy astrocytes in four cortical regions, one case contained granular fuzzy astrocytes in two cortical regions, and two cases contained occasional grey matter granular fuzzy astrocytes in one cortical region only (Fig. 2R).

\section{Immunostaining for $A \beta$, alpha-synuclein, pTDP-43 and p62}

\section{Herpes simplex virus encephalitis}

Four HSV encephalitis cases contained $\mathrm{A} \beta$ plaques consistent with Thal phase 1 ( 4 cases) (Fig. 3I-K). One case showed a few $\mathrm{A} \beta$ deposits only in the occipital cortex and circumscribed in the striatum (Fig. 3K) and not in other regions, altogether classified as Thal phase 1 . A $\beta$ plaques were absent in 8 cases, and Thal phase could not be evaluated in one case as cortical blocks were unavailable. $A \beta$ deposition in blood vessels in the frontal cortex was found in one case only (Fig. 3L). Brainstem and cortical Lewy bodies were observed in one HSV case (Braak stage 5; Fig. 3M, N). Lewy bodies were not observed in remaining cases, although we cannot exclude Braak stage 1 in three cases and Braak stages less than 3 in three cases due to the lack of representative brainstem regions. In addition to p62-immunopositive reactive astrocytes following the distribution of cortical hypoxic/ischemic damage (Fig. 3O, $\mathrm{P}$ ), immunostaining with $\mathrm{p} 62$ revealed similar neuropathological features as observed above.

\section{Neurosyphilis}

Eleven neurosyphilis cases contained $A \beta$ plaques, which varied in density and anatomical distribution (Fig. 2U-X). Three of these cases also contained $A \beta$ deposition in blood vessels, which were confined to cortical regions (Fig. 2U, $\mathrm{V})$ and the amygdala. Two cases contained alpha-synuclein deposits. In the first case, which had Braak NFT stage VI, Lewy bodies and Lewy neurites (Fig. 2Y) were present in the amygdala. Alpha-synuclein-immunoreactivity was absent in the basal ganglia and all cortical regions examined. The brainstem was unavailable in this case. In the second case, Lewy bodies and Lewy neurites were observed in the substantia nigra (Fig. 2Z-B'). Alpha-synuclein-immunoreactivity was absent in the hippocampus and all cortical regions examined, corresponding to Braak stage 3. Other brainstem regions and the amygdala were not available in this case. pTDP-43 immunostaining was absent in all cases in all brain regions examined. Immunostaining with p62 revealed similar neuropathological features as observed with phosphorylated-tau and alpha-synuclein.

\section{Discussion}

The present study investigated the prevalence and distribution of neurodegenerative proteinopathies and co-existing ARTAG in patients with infection-induced acute or chronic inflammation associated with HSV encephalitis and neurosyphilis. HSV-1 and T. pallidum are capable of remaining undetected by the immune system, leading to chronic infection, inflammation and, as theorized, subsequent deposition of $\mathrm{A} \beta$ and abnormal tau phosphorylation in the brain (Miklossy 2015; Laval and Enquist 2021). HSV encephalitis and neurosyphilis have been previously associated with $\mathrm{AD}$ pathology and increased for risk developing AD. This study now broadens the spectrum of proteinopathies associated with HSV encephalitis and neurosyphilis. Almost all patients had mild AD pathology and most of these had additional AT8 immunoreactivity in regions associated with inflammation expanding beyond the regions expected to be involved from their corresponding Braak NFT stage. This observation highlights the complexity of these disorders both pathologically and clinically following acute and chronic infection.

This study demonstrated that HSV infection-induced acute inflammation associated with a rapid disease course (9 and 16 days) was already associated with phosphorylated-tau-(AT8) immunopositive neurons in brain regions with inflammation. This pathology was in addition to tau pathology in the medial temporal lobe associated with AD neuropathological change (Montine et al. 2012) and involved regions, such as the substantia nigra, which are not affected in early Braak stages of neurofibrillary degeneration. Indeed, these cases had an absence of $A \beta$ plaques and $\mathrm{A} \beta$ deposition in vessels in all regions examined and few neurofibrillary tangles in the medial temporal lobe consistent with Braak stage I. HSV-1 in the brain is thought to cause inflammation and subsequent $A \beta$ deposition and tau phosphorylation (Laval and Enquist 2021), and whether infection-induced acute inflammation is sufficient to cause tau deposition in regions associated with inflammation require further investigation in a larger case series. However, in addition to HSV-1, a range of viruses are associated with neuroinfections or other immune-mediated mechanisms and tau deposition in the brain, but most of these occur months to years after initial infection or presentation of an autoimmune process. Postencephalitic parkinsonism (PEP) occurs years to decades after encephalitis lethargica (Hoffman and Vilensky 2017). In addition to widespread inflammation, PEP is characterised by neurofibrillary tangles and neuronal loss 

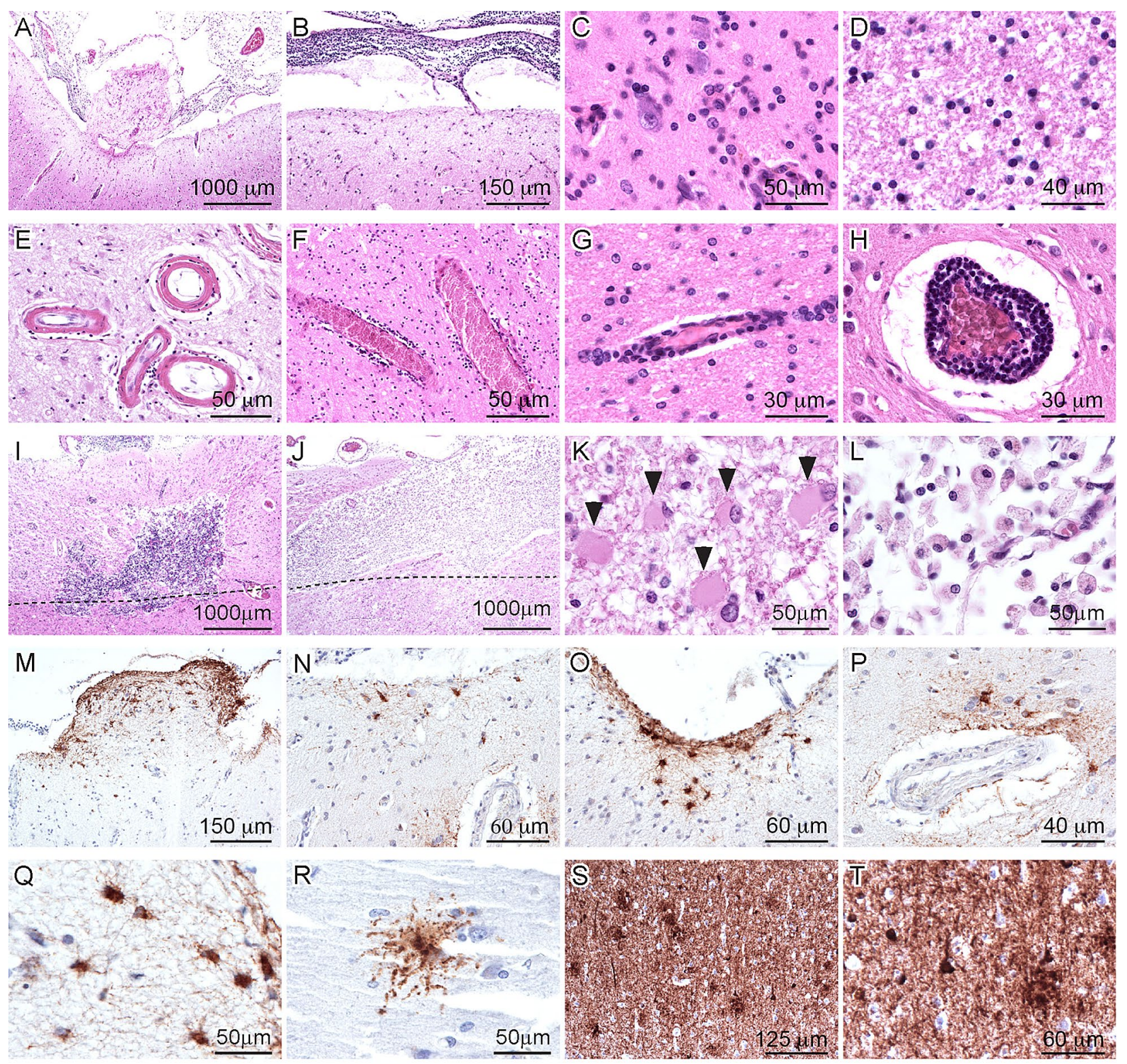

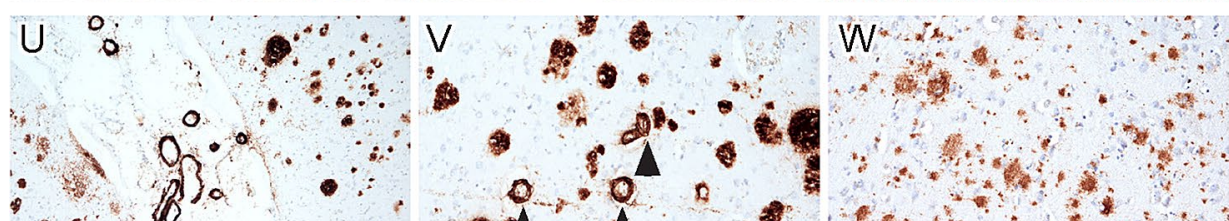

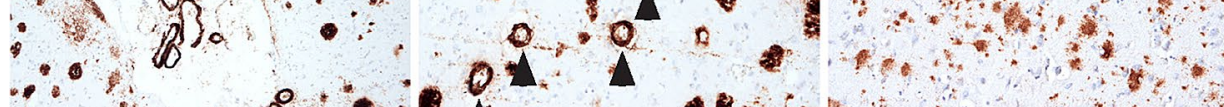

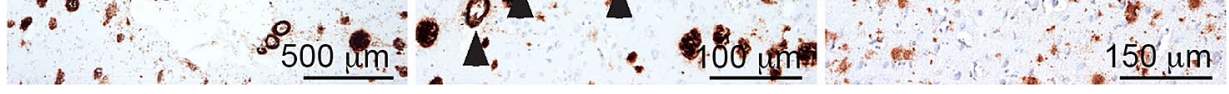
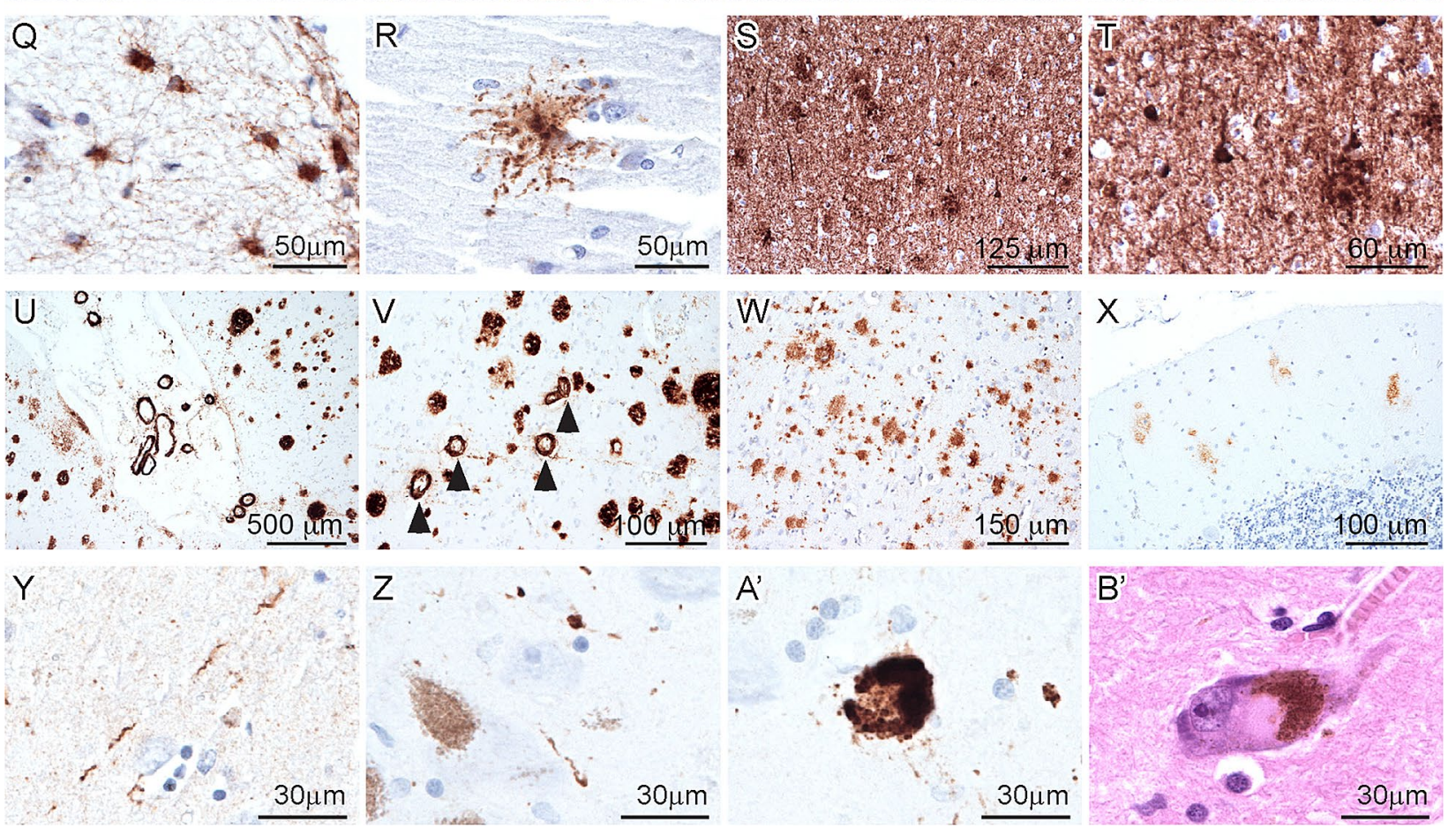
४Fig. 2 Histological and neuropathological features in neurosyphilis cases. Widespread leptomeningeal (A, B) and parenchymal (C, D), and perivascular inflammation $(\mathbf{E}-\mathbf{H})$ was observed. Cortical extrusions (A, M) were observed in some regions. Cortical infarcts (I, J) with gemistocytic astrocytes $(\mathbf{K})$ and macrophages $(\mathbf{L})$ were found in multiple regions. Phosphorylated tau-immunopositive thorn-shaped astrocytes associated with subpial (M-O) and perivascular (P) ageing-related tau astrogliopathy (ARTAG). Characteristic phosphorylated-tau-immunopositive thorn-shaped $(\mathbf{Q})$ and granular fuzzy $(\mathbf{R})$ astrocytes in a case with cortical ARTAG. Neurofibrillary tangles and neuritic plaques in Bielschowsky Silver-stained sections $(\mathbf{S}, \mathbf{T})$ in the temporal cortex in a case with Alzheimer's disease. A $\beta$ plaques in the cortex $(\mathbf{U}, \mathbf{V})$, basal ganglia $(\mathbf{W})$ and cerebellum $(\mathbf{X})$. A $\beta$ deposition in blood vessels ( $\mathbf{U}$ and $\mathbf{V}$, arrowheads) was confined to cortical regions and amygdala. $\alpha$-synuclein-immunopositive Lewy neurites $(\mathbf{Y}, \mathbf{Z})$ and Lewy bodies $\left(\mathbf{A}^{\prime}, \mathbf{B}^{\prime}\right)$ in the amygdala $(\mathbf{Y})$ and substantia nigra $\left(\mathbf{Z}-\mathbf{B}^{\prime}\right)$. Dashed line in I and $\mathrm{J}$ represents the grey-white border. Immunostained sections are counterstained with Haematoxylin

in the substantia nigra, and the presence of neurofibrillary tangles in the hippocampus and neocortex with few or an absence of A $\beta$ plaques (Geddes et al. 1993; Jellinger 2009). In particular, Kurt Jellinger has made significant contributions to the understanding of the biochemical composition, morphology and anatomical distribution of tau pathology in PEP (Jellinger 2009), which allows its differentiation from other tau depositing disorders. Neurofibrillary tangles in the substantia nigra have also been reported in West Nile virus encephalomyelitis (Schafernak and Bigio 2006) and involving other regions in subacute sclerosing panencephalitis caused by the measles morbillivirus together with glial tau deposits (Ikeda et al. 1995; Iwatsubo et al. 1994). Nodding syndrome is a neurological condition affecting children in east Africa, which is characterised by widespread tau pathology in the form of neurofibrillary tangles, pre-tangles, dot-like grains and neuropil threads (Pollanen et al. 2018). While the aetiology of this disorder remains to be determined, neurotrophic viruses or other infectious agents have been discussed as an aetiology (Spencer et al. 2016). Together, these studies indicate that both virus-induced acute and chronic inflammation are associated with tau deposition, although disease mechanisms involved require further elucidation.

Following initial peripheral infection, the ability of HSV-1 to cause encephalitis is well established. However, the mechanism/s of how HSV-1 enters the brain remain debated, and indirect and direct pathways have been suggested. Indirect pathways for viral entry into the CNS include retrograde transport of HSV-1 via the trigeminal nerve to the brainstem, which is the most likely cause, or the spread of HSV-1 occurs via the olfactory tract (Jennische et al. 2015; Laval and Enquist 2021). Alternatively, direct HSV-1 infections from the periphery or reactivation of latent HSV-1 in the brain are also suggested mechanisms for viral entry into the brain (Laval and Enquist 2021). Reactivation of HSV-1 can cause persistent inflammation and subsequent neurodegeneration. Interestingly, three patients in the current study only showed equivocal HSV immunoreactivity and HSV immunoreactivity was absent in one patient, and it has been suggested that reactivation of latent HSV-1 in the periphery might be sufficient to cause inflammation of the CNS in the absence of detectable HSV-1 in the brain (Laval and Enquist 2021).

Spirochetes are strongly neurotropic and are well-established causes of neurological symptoms. T. pallidum persists in the brain, evading the immune system, and causes infection-induced chronic inflammation and subsequent $\mathrm{A} \beta$ deposition and tau phosphorylation, and neurodegeneration years after primary infection (Radolf et al. 2016; Miklossy 2015). In addition, other spirochetes have been associated with $\mathrm{AD}$ and are found in the brains of $\mathrm{AD}$ patients (Miklossy et al. 2004; Riviere et al. 2002; Miklossy 2011). The current study demonstrated that T. pallidum infectioninduced chronic inflammation was associated with phosphorylated-tau (AT8) immunoreactive neurons expanding beyond what is expected in the Braak stages observed in almost all cases and many of these cases had additional tau pathology in brain regions associated with inflammation. Following chronic infection with T. pallidum, activation of the innate and adaptive immune systems is thought to trigger subsequent $\mathrm{A} \beta$ deposition (Miklossy 2011) and approximately half of all cases in the current study had A $\beta$ plaques. Despite widespread and prominent leptomeningeal and parenchymal inflammation with severe gliosis observed in all neurosyphilis cases, further research is needed to explore the role of these two neurodegenerative proteins following chronic bacterial infection.

Tau-immunopositive astrocytes are commonly observed in the ageing human brain and in neurodegenerative disorders (Schultz et al. 2004; Kovacs et al. 2017). In 2016, consensus recommendations for the identification and evaluation of ARTAG were established to unify the nomenclature and standardise the classification into different types according to the morphology and anatomical distribution of astrocytic inclusions (Kovacs et al. 2016). It has been suggested that the preferential location of tau-immunopositive astrocytes in subpial and perivascular regions could be caused by exposure to CSF or extravasated plasma proteins by compromised blood-brain barrier permeability (Lace et al. 2012; Schultz et al. 2004), which is commonly observed in the elderly and in neurodegenerative diseases and likely to predispose these individuals to viral and bacterial infections. Interestingly, the majority of cases with neurosyphilis had prominent subpial and perivascular gliosis, and leptomeningeal inflammation with the absence of subpial ARTAG. While additional studies are required in a larger case series, the current study indicates that tau-containing astrocytes are unlikely to be affected by this mechanism. Studies have now demonstrated that ARTAG is observed in up to 
Table 4 Summary of neuropathological features in patients with herpes simplex virus encephalitis

\begin{tabular}{|c|c|c|c|c|c|c|c|c|c|c|c|c|c|}
\hline & \multicolumn{13}{|c|}{ Case no } \\
\hline & 1 & 2 & 3 & 4 & 5 & 6 & 7 & 8 & 9 & 10 & 11 & 12 & 13 \\
\hline Sex & $\mathrm{F}$ & $\mathrm{F}$ & M & $\mathrm{F}$ & M & M & $\mathrm{F}$ & $\mathrm{F}$ & M & $\mathrm{F}$ & M & M & M \\
\hline Age at death $(y)$ & 55 & 56 & 42 & 66 & 58 & 63 & 58 & 51 & 65 & 24 & 65 & 41 & 49 \\
\hline Disease duration & $9 \mathrm{~d}$ & $11 d$ & $12 d$ & $16 \mathrm{~d}$ & $23 d$ & $45 \mathrm{~d}$ & $7 \mathrm{~m}$ & $1 \mathrm{y}$ & $2 y$ & $3 y$ & $6 y$ & na & na \\
\hline Thal phase & 0 & 0 & 0 & 0 & 1 & 1 & 1 & 0 & 0 & na & 1 & 0 & 0 \\
\hline $\mathrm{A} \beta$ in vessels & - & - & - & - & + & - & - & - & - & na & - & - & - \\
\hline Braak NFT stage & $1 \mathrm{a}$ & 0 & 0 & I & 0 & na & I & I & II & 0 & III & 0 & 0 \\
\hline ARTAG & - & - & - & + & - & - & - & - & - & - & - & - & - \\
\hline Alpha-synuclein & - & - & 0 & 0 & - & - & - & 0 & +(B5) & 0 & - & - & - \\
\hline \multicolumn{14}{|l|}{ Neuronal AT8 IR } \\
\hline Neocortex & - & - & - & + & - & - & - & na & - & na & + & - & - \\
\hline Hippocampus/MTL & na & - & - & + & - & na & + & + & + & - & + & - & - \\
\hline Basal ganglia & + & - & na & na & - & - & - & na & na & na & na & - & - \\
\hline Thalamus/hypothalamus & na & - & - & + & na & na & na & na & - & na & na & na & na \\
\hline Midbrain & + & - & na & na & - & na & na & - & na & na & - & + & - \\
\hline Pons & + & - & na & na & na & na & na & na & na & na & na & na & na \\
\hline Medulla & na & na & + & + & na & na & na & - & - & - & na & na & na \\
\hline Cerebellum & na & na & na & na & na & na & na & na & na & na & na & na & na \\
\hline
\end{tabular}

na Not available, alpha-synuclein, Case 9 had Lewy bodies in the cortex and fulfilled criteria for Braak Lewy body stage 5 (B5); MTL medial temporal lobe; + positive, - negative; IR immunoreactivity, $d$ days, $m$ months, $y$ years
$50 \%$ of control cases and $70 \%$ of cases with a neurodegenerative disorder (Kovacs et al. 2017), and recently cortical ARTAG has been reported in approximately one-third of cases from a large European community-based population (Forrest et al. 2019b). Based on these studies, the prevalence of ARTAG in the current cohorts was lower than expected e.g. one (out of 13) HSV encephalitis case and five (out of 23 ) neurosyphilis cases. However, the medial temporal lobe (amygdala and hippocampus), which is a known ARTAG predilection area, was not available in all cases and the true prevalence of ARTAG in these cohorts is likely to be underestimated. In addition, the average age of death in the HSV encephalopathy cohort was $52 \pm 12$ years, and ARTAG is most commonly observed in individuals $>60$ years (Kovacs et al. 2016) and is less common in individuals $<60$ years of age. In addition to ARTAG, limbic-predominant age-related TDP-43 encephalopathy (LATE) is a common and recently described age-related pathology associated with TDP-43 pathology in limbic regions (Nelson et al. 2019). However, pTDP-43-immunoreactivity was not observed in any case in the current study in the brain regions examined.

In the current study, one patient with HSV encephalitis and 2 patients with neurosyphilis contained Lewy bodies and were associated with a range of clinical symptoms. One patient with HSV encephalitis (Case \# 7) had Braak Lewy body stage 5 . Although Braak Lewy body stage 4 corresponds to clinical parkinsonism (Braak et al. 2003; Halliday et al. 2011), these symptoms were not reported in this case. The presence of Lewy bodies has also been associated with anosmia, REM sleep behaviour disorder and systematised delusions, but these features were not documented in the current cohort. Cerebral amyloid angiopathy (CAA) was only found in a small number of cases. CAA is common in the brains of elderly individuals (Arvanitakis et al. 2011; Boyle et al. 2015) and those with Alzheimer's disease (Attems and Jellinger 2004; Attems et al. 2011). A recent study has demonstrated that the presence of CAA can be used to differentiate Lewy body dementia and Parkinson's disease dementia, and is associated with cognitive impairment and faster disease progression (Jellinger 2021).

This pathological study in patients with viral- and bacterial-induced infections associated with acute and chronic inflammation demonstrated the deposition of neurodegenerative proteins in regions associated with inflammation and in broader regions than expected from the Braak NFT stage. However, larger case series are required to determine the mechanisms of how these infectious agents trigger the 

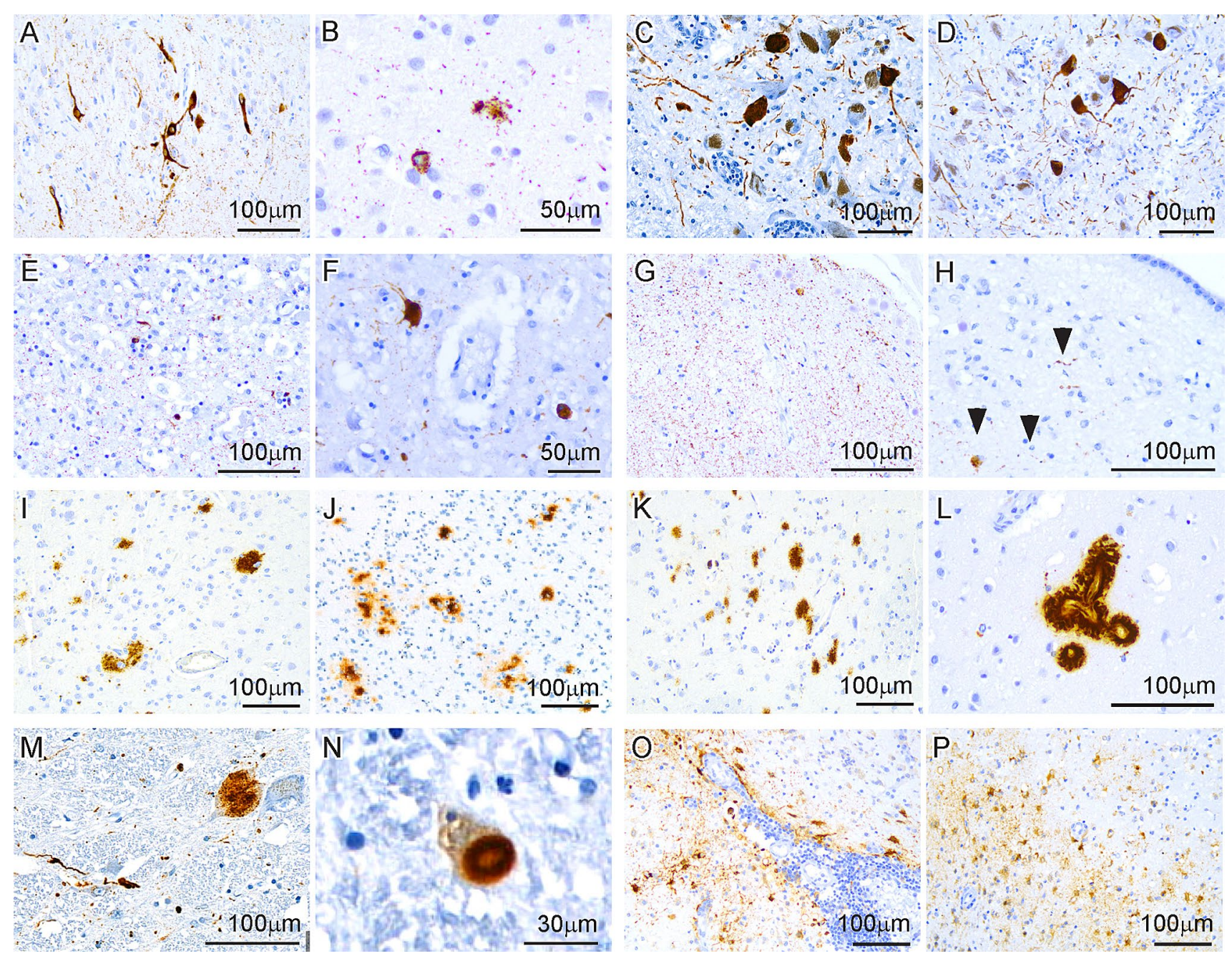

Fig. 3 Neuropathological features in cases with herpes simplex virus encephalitis. Phosphorylated tau-immunopositive neurons and neuropil threads (arrowheads in $\mathrm{H}$ ) in the hippocampus (A, E), substantia nigra $(\mathbf{C}, \mathbf{D})$, temporal cortex $(\mathbf{B}, \mathbf{F})$ and subpial $(\mathbf{G})$ and subependymal areas $(\mathbf{H})$. A $\beta$ plaques in the temporal $(\mathbf{I})$ and occipital $(\mathbf{J})$ corti-

deposition or accelerate the deposition of these neurodegenerative proteins. In addition, this study has obvious implications for COVID-19 patients with chronic and/or post-infectious neurological and psychiatric symptoms, and encephalitis. Almost all published reports to date have focused on inflammatory, hypoxic, cerebrovascular events in the brain and it remains to be determined whether these clinical symptoms are directly related to viral entry into the brain. The presence of SARS-CoV virus has been detected in the brain of COVID-19 patients and a number of mechanisms on how the virus gains entry to the CNS

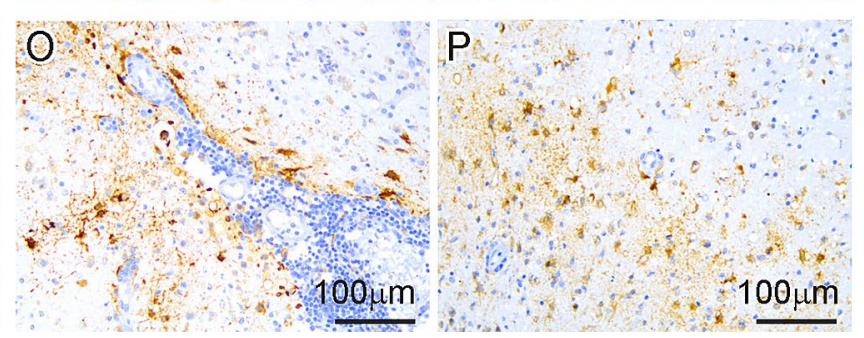

ces and basal ganglia $(\mathbf{K})$. A $\beta$ was associated with some vessels in the frontal cortex (L). $\alpha$-synuclein $(\mathbf{M})$ and p62 (N) -immuno-positive Lewy-related pathology in the locus coeruleus. P62-immunopositive astrocytes associated with vessels $(\mathbf{O})$ and areas of inflammation $(\mathbf{P})$. All sections are counterstained with Haematoxylin.

have been suggested (Al-Sarraj et al. 2021; Guerrero et al. 2021; Sieracka et al. 2021). Inflammation in the brains of patients with COVID-19 is yet to be linked to the deposition of infection-induced inflammation and whether this induces subsequent deposition of neurodegenerative proteins. However, it is known that patients with dementia are at increased risk of COVID-19 compared to those without dementia, and experience a worse prognosis (Wang et al. 2021) and future studies are likely to address this question. There are currently limited observations of the prevalence and anatomical distribution of neurodegenerative proteins found in patients with COVID-19, which may be of relevance to future studies 
Table 5 Summary of neuropathological features in patients with neurosyphilis

\begin{tabular}{|c|c|c|c|c|c|c|c|c|c|c|c|c|c|c|c|c|c|c|c|c|c|c|c|}
\hline & \multicolumn{23}{|c|}{ Case no } \\
\hline & 1 & 2 & 3 & 4 & 5 & 6 & 7 & 8 & 9 & 10 & 11 & 12 & 13 & 14 & 15 & 16 & 17 & 18 & 19 & 20 & 21 & 22 & 2 \\
\hline Sex & $\mathrm{F}$ & M & $\mathrm{F}$ & M & $\mathrm{F}$ & $\mathrm{F}$ & M & M & $\mathrm{F}$ & M & M & $\mathrm{F}$ & M & M & $\mathrm{F}$ & M & M & M & $\mathrm{M}$ & $\mathrm{F}$ & M & M & M \\
\hline Age at death (y) & 45 & 64 & 69 & 36 & 36 & 38 & 42 & 58 & 65 & 69 & 75 & 76 & 48 & 65 & 67 & 69 & 69 & 72 & 86 & 43 & 50 & 70 & 1 \\
\hline Disease duration (y) & 1 & 1 & 1 & 2 & 2 & 2 & 2 & 2 & 2 & 2 & 2 & 3 & 4 & 4 & 4 & 4 & 4 & 4 & 4 & 5 & 5 & 5 & 5 \\
\hline Thal phase & 1 & 1 & 0 & 0 & 1 & 0 & 0 & 0 & 0 & 1 & 1 & 3 & 0 & 2 & 0 & 1 & 0 & 0 & 1 & 0 & 0 & 5 & 2 \\
\hline A $\beta$ in vessels & - & - & - & - & - & - & - & - & - & - & - & - & - & - & - & + & - & - & - & - & - & + & $T$ \\
\hline Braak NFT stage & na & na & na & 0 & I & 0 & II & I & II & I & na & II & II & III & I & II & III & III & na & I & na & VI & II \\
\hline Cortical ARTAG & - & + & + & - & + & - & - & - & - & - & + & + & - & - & - & - & - & - & - & - & - & - & - \\
\hline Alpha-synuclein ${ }^{\mathrm{a}}$ & - & - & - & - & - & - & - & - & - & - & - & - & - & $+(\mathrm{B} 3)$ & - & - & - & - & - & - & - & $+(\mathrm{A})$ & - \\
\hline pTDP-43 & - & - & - & - & - & - & - & - & - & - & - & - & - & - & - & - & - & - & - & - & - & - & - \\
\hline \multicolumn{24}{|l|}{ Neuronal AT8 IR } \\
\hline Neocortex & - & + & + & - & + & - & + & + & - & + & + & + & + & + & + & + & + & + & + & + & - & + & + \\
\hline Hippocampus/MTL & na & na & na & - & + & - & + & + & + & + & na & + & + & + & + & + & + & + & na & + & na & + & + \\
\hline Basal ganglia & na & na & na & - & na & - & + & na & na & na & na & - & na & na & - & na & na & + & na & na & na & + & $\mathrm{n}$ \\
\hline Thalamus/hypothalamus & na & na & - & na & - & na & na & na & na & na & na & na & - & + & + & na & na & na & na & na & na & na & $\mathrm{n}$ \\
\hline Midbrain & na & na & na & na & na & na & na & na & na & na & na & na & na & na & na & + & na & na & na & na & na & na & \\
\hline Pons & na & na & na & na & na & na & na & + & na & na & na & na & na & na & na & + & + & na & + & na & na & na & \\
\hline Medulla & na & na & na & na & - & na & + & na & na & na & na & na & na & na & + & na & na & - & na & na & na & na & na \\
\hline Cerebellum & na & na & na & na & - & na & na & na & na & na & na & - & na & na & na & na & na & na & na & na & na & na & \\
\hline
\end{tabular}

$M T L$ medial temporal lobe, $n a$ not available; + positive, - negative, IR immunoreactivity, $y$ years

${ }^{a}$ Case 14 had Lewy bodies in the substantia nigra and fulfilled criteria for Braak Lewy body stage 3 (B3), and Case 22 had Lewy bodies confined to the amygdala $(\mathrm{A})$

focusing on the underlying and prolonged nature of neurological and psychiatric symptoms in these patients.

Supplementary Information The online version contains supplementary material available at https://doi.org/10.1007/s00702-021-02371-7.

Author contributions KD: Concept and design of the study, acquisition of data and analysis, interpretation of data, drafted the manuscript, read and approved final version of manuscript for submission. SF: Concept and design of the study, acquisition of data and analysis, interpretation of data, drafted the manuscript, read and approved final version of manuscript for submission. Responsible for data and accuracy of research. IK: Review of clinical files and acquisition of clinical data, read and approved the final version of manuscript for submission. IE: Acquisition of neuropathological data, read and approved the final version of manuscript for submission. SS: Acquisition of neuropathological data, read and approved the final version of manuscript for submission. KT: Review of clinical files and acquisition of clinical data, read and approved the final version of manuscript for submission. KM: Interpretation of data, read and approved the final version of manuscript for submission. GK: Concept and design of the study, acquisition of data and analysis, interpretation of data, drafted the manuscript, read and approved final version of manuscript for submission. Responsible for data and accuracy of research.

Funding GGK is supported by the Rossy foundation and Safra foundation and the Karl Golser Prize.

Availability of data and material Any anonymised data used in this study will be shared by request from any qualified investigator.
Code Availability Not applicable.

\section{Declarations}

Conflict of interest The authors declare that they have no conflict of interest.

Ethical approval This study was approved by the Regional and Institutional Committee of Science and Research Ethics (Nr. 34/2016), Semmelweis University.

Consent to participate Not applicable.

Consent for publication Not applicable.

\section{References}

Al-Sarraj S, Troakes C, Hanley B, Osborn M, Richardson MP, Hotopf M, Bullmore E, Everall IP (2021) Invited review: the spectrum of neuropathology in COVID-19. Neuropathol Appl Neurobiol 47(1):3-16. https://doi.org/10.1111/nan.12667

Arvanitakis Z, Leurgans SE, Wang Z, Wilson RS, Bennett DA, Schneider JA (2011) Cerebral amyloid angiopathy pathology and cognitive domains in older persons. Ann Neurol 69(2):320-327

Attems J, Jellinger KA (2004) Only cerebral capillary amyloid angiopathy correlates with Alzheimer pathology—a pilot study. 
Acta Neuropathol 107(2):83-90. https://doi.org/10.1007/ s00401-003-0796-9

Attems J, Jellinger K, Thal DR, Van Nostrand W (2011) Review: sporadic cerebral amyloid angiopathy. Neuropathol Appl Neurobiol 37(1):75-93. https://doi.org/10.1111/j.1365-2990.2010.01137.x

Boyle PA, Yu L, Nag S, Leurgans S, Wilson RS, Bennett DA, Schneider JA (2015) Cerebral amyloid angiopathy and cognitive outcomes in community-based older persons. Neurology 85(22):1930-1936

Braak H, Braak E (1991) Neuropathological stageing of Alzheimerrelated changes. Acta Neuropathol 82(4):239-259. https://doi.org/ 10.1007/BF00308809

Braak H, Del Tredici K, Rub U, de Vos RA, Jansen Steur EN, Braak E (2003) Staging of brain pathology related to sporadic Parkinson's disease. Neurobiol Aging 24(2):197-211. https://doi.org/10.1016/ s0197-4580(02)00065-9

Deckert M (2015) Bacterial infections. Greenfield's neuropathology, vol 2. CRC Press Taylor \& Francis, Boca Raton London New York

Féart C, Helmer C, Fleury H, Béjot Y, Ritchie K, Amouyel P, SchraenMaschke S, Buée L, Lambert JC, Letenneur L, Dartigues JF (2011) Association between IgM anti-herpes simplex virus and plasma amyloid-beta levels. PLoS ONE 6(12):e29480

Forrest SL, Kril JJ, Halliday GM (2019a) Cellular and regional vulnerability in frontotemporal tauopathies. Acta Neuropathol 138(5):705-727. https://doi.org/10.1007/s00401-019-02035-7

Forrest SL, Kril JJ, Wagner S, Hönigschnabl S, Reiner A, Fischer P, Kovacs GG (2019b) Chronic traumatic encephalopathy (CTE) is absent from a European community-based aging cohort while cortical aging-related tau astrogliopathy (ARTAG) is highly prevalent. J Neuropathol Exp Neurol 78(5):398-405. https://doi.org/ 10.1093/jnen/nlz017

Geddes JF, Hughes AJ, Lees AJ, Daniel SE (1993) Pathological overlap in cases of parkinsonism associated with neurofibrillary tangles. A study of recent cases of postencephalitic parkinsonism and comparison with progressive supranuclear palsy and Guamanian parkinsonism-dementia complex. Brain 116(Pt 1):281-302. https:// doi.org/10.1093/brain/116.1.281

Guerrero JI, Barragán LA, Martínez JD, Montoya JP, Peña A, Sobrino FE, Tovar-Spinoza Z, Ghotme KA (2021) Central and peripheral nervous system involvement by COVID-19: a systematic review of the pathophysiology, clinical manifestations, neuropathology, neuroimaging, electrophysiology, and cerebrospinal fluid findings. BMC Infect Dis 21(1):515

Halliday GM, Holton JL, Revesz T, Dickson DW (2011) Neuropathology underlying clinical variability in patients with synucleinopathies. Acta Neuropathol 122(2):187-204. https://doi.org/10.1007/ s00401-011-0852-9

Harris SA, Harris EA (2015) Herpes simplex virus type 1 and other pathogens are key causative factors in sporadic Alzheimer's disease. J Alzheimers Dis 48(2):319-353

Hoffman LA, Vilensky JA (2017) Encephalitis lethargica: 100 years after the epidemic. Brain 140(8):2246-2251. https://doi.org/10. 1093/brain/awx177

Ikeda K, Akiyama H, Kondo H, Arai T, Arai N, Yagishita S (1995) Numerous glial fibrillary tangles in oligodendroglia in cases of subacute sclerosing panencephalitis with neurofibrillary tangles. Neurosci Lett 194(1-2):133-135. https://doi.org/10.1016/03043940(95)11713-7

Iwatsubo T, Hasegawa M, Ihara Y (1994) Neuronal and glial taupositive inclusions in diverse neurologic diseases share common phosphorylation characteristics. Acta Neuropathol 88(2):129-136. https://doi.org/10.1007/bf00294505

Jamieson GA, Maitland NJ, Wilcock GK, Craske J, Itzhaki RF (1991) Latent herpes simplex virus type 1 in normal and Alzheimer's disease brains. J Med Virol 33(4):224-227. https://doi.org/10. 1002/jmv. 1890330403
Jellinger KA (2009) Absence of alpha-synuclein pathology in postencephalitic parkinsonism. Acta Neuropathol 118(3):371-379. https://doi.org/10.1007/s00401-009-0537-9

Jellinger KA (2021) Significance of cerebral amyloid angiopathy and other co-morbidities in Lewy body diseases. J Neural Transm (vienna) 128(5):687-699. https://doi.org/10.1007/ s00702-021-02345-9

Jennische E, Eriksson CE, Lange S, Trybala E, Bergström T (2015) The anterior commissure is a pathway for contralateral spread of herpes simplex virus type 1 after olfactory tract infection. J Neurovirol 21(2):129-147. https://doi.org/10.1007/s13365-014-0312-0

Kovacs GG (2019) Are comorbidities compatible with a molecular pathological classification of neurodegenerative diseases? Curr Opin Neurol 32(2):279-291. https://doi.org/10.1097/wco.00000 00000000664

Kovacs GG, Ferrer I, Grinberg LT, Alafuzoff I, Attems J, Budka H, Cairns NJ, Crary JF, Duyckaerts C, Ghetti B, Halliday GM, Ironside JW, Love S, Mackenzie IR, Munoz DG, Murray ME, Nelson PT, Takahashi H, Trojanowski JQ, Ansorge O, Arzberger T, Baborie A, Beach TG, Bieniek KF, Bigio EH, Bodi I, Dugger BN, Feany M, Gelpi E, Gentleman SM, Giaccone G, Hatanpaa KJ, Heale R, Hof PR, Hofer M, Hortobagyi T, Jellinger K, Jicha GA, Ince P, Kofler J, Kovari E, Kril JJ, Mann DM, Matej R, McKee AC, McLean C, Milenkovic I, Montine TJ, Murayama S, Lee EB, Rahimi J, Rodriguez RD, Rozemuller A, Schneider JA, Schultz C, Seeley W, Seilhean D, Smith C, Tagliavini F, Takao M, Thal DR, Toledo JB, Tolnay M, Troncoso JC, Vinters HV, Weis S, Wharton SB, White CL 3rd, Wisniewski T, Woulfe JM, Yamada M, Dickson DW (2016) Aging-related tau astrogliopathy (ARTAG): harmonized evaluation strategy. Acta Neuropathol 131(1):87-102. https://doi.org/10.1007/s00401-015-1509-x

Kovacs GG, Robinson JL, Xie SX, Lee EB, Grossman M, Wolk DA, Irwin DJ, Weintraub D, Kim CF, Schuck T, Yousef A, Wagner ST, Suh E, Van Deerlin VM, Lee VM, Trojanowski JQ (2017) Evaluating the patterns of aging-related tau astrogliopathy unravels novel insights into brain aging and neurodegenerative diseases. J Neuropathol Exp Neurol 76(4):270-288

Kovacs GG, Xie SX, Robinson JL, Lee EB, Smith DH, Schuck T, Lee VM, Trojanowski JQ (2018) Sequential stages and distribution patterns of aging-related tau astrogliopathy (ARTAG) in the human brain. Acta Neuropathol Commun 6(1):50

Lace G, Ince PG, Brayne C, Savva GM, Matthews FE, de Silva R, Simpson JE, Wharton SB (2012) Mesial temporal astrocyte tau pathology in the MRC-CFAS ageing brain cohort. Dement Geriatr Cogn Disord 34(1):15-24. https://doi.org/10.1159/000341581

Laval K, Enquist LW (2021) The potential role of herpes simplex virus type 1 and neuroinflammation in the pathogenesis of Alzheimer's disease. Front Neurol 12:658695

Letenneur L, Pérès K, Fleury H, Garrigue I, Barberger-Gateau P, Helmer C, Orgogozo JM, Gauthier S, Dartigues JF (2008) Seropositivity to herpes simplex virus antibodies and risk of Alzheimer's disease: a population-based cohort study. PLoS ONE 3(11):e3637

Lin WR, Shang D, Wilcock GK, Itzhaki RF (1995) Alzheimer's disease, herpes simplex virus type 1, cold sores and apolipoprotein E4. Biochem Soc Trans 23(4):594S. https://doi.org/10.1042/bst02 $3594 \mathrm{~s}$

Looker KJ, Magaret AS, May MT, Turner KM, Vickerman P, Gottlieb SL, Newman LM (2015) Global and regional estimates of prevalent and incident herpes simplex virus type 1 infections in 2012. PLoS ONE 10(10): e0140765

Maheshwari P, Eslick GD (2015) Bacterial infection and Alzheimer's disease: a meta-analysis. J Alzheimers Dis 43(3):957-966. https:// doi.org/10.3233/jad-140621 
Miklossy J (2011) Alzheimer's disease-a neurospirochetosis. Analysis of the evidence following Koch's and Hill's criteria. J Neuroinflammation 8:90

Miklossy J (2015) Historic evidence to support a causal relationship between spirochetal infections and Alzheimer's disease. Front Aging Neurosci 7:46

Miklossy J, Khalili K, Gern L, Ericson RL, Darekar P, Bolle L, Hurlimann J, Paster BJ (2004) Borrelia burgdorferi persists in the brain in chronic lyme neuroborreliosis and may be associated with Alzheimer disease. J Alzheimers Dis 6(6):639-649. https://doi.org/ 10.3233/jad-2004-6608

Montine TJ, Phelps CH, Beach TG, Bigio EH, Cairns NJ, Dickson DW, Duyckaerts C, Frosch MP, Masliah E, Mirra SS, Nelson PT, Schneider JA, Thal DR, Trojanowski JQ, Vinters HV, Hyman BT (2012) National institute on aging-Alzheimer's association guidelines for the neuropathologic assessment of Alzheimer's disease: a practical approach. Acta Neuropathol 123(1):1-11. https://doi. org/10.1007/s00401-011-0910-3

Mrdjen D, Fox EJ, Bukhari SA, Montine KS, Bendall SC, Montine TJ (2019) The basis of cellular and regional vulnerability in Alzheimer's disease. Acta Neuropathol 138(5):729-749

Nelson PT, Dickson DW, Trojanowski JQ, Jack CR, Boyle PA, Arfanakis K, Rademakers R, Alafuzoff I, Attems J, Brayne C, CoyleGilchrist ITS, Chui HC, Fardo DW, Flanagan ME, Halliday G, Hokkanen SRK, Hunter S, Jicha GA, Katsumata Y, Kawas CH, Keene CD, Kovacs GG, Kukull WA, Levey AI, Makkinejad N, Montine TJ, Murayama S, Murray ME, Nag S, Rissman RA, Seeley WW, Sperling RA, White Iii CL, Yu L, Schneider JA (2019) Limbic-predominant age-related TDP-43 encephalopathy (LATE): consensus working group report. Brain 142(6):1503-1527

Pollanen MS, Onzivua S, Robertson J, McKeever PM, Olawa F, Kitara DL, Fong A (2018) Nodding syndrome in Uganda is a tauopathy. Acta Neuropathol 136(5):691-697

Radolf JD, Deka RK, Anand A, Šmajs D, Norgard MV, Yang XF (2016) Treponema pallidum, the syphilis spirochete: making a living as a stealth pathogen. Nat Rev Microbiol 14(12):744-759

Riviere GR, Riviere KH, Smith KS (2002) Molecular and immunological evidence of oral Treponema in the human brain and their association with Alzheimer's disease. Oral Microbiol Immunol 17(2):113-118. https://doi.org/10.1046/j.0902-0055.2001.00100.x

Sait A, Angeli C, Doig AJ, Day PJR (2021) Viral involvement in Alzheimer's disease. ACS Chem Neurosci 12(7):1049-1060

Schafernak KT, Bigio EH (2006) West Nile virus encephalomyelitis with polio-like paralysis \& nigral degeneration. Can J Neurol Sci 33(4):407-410. https://doi.org/10.1017/s0317167100005370

Schultz C, Ghebremedhin E, Del Tredici K, Rüb U, Braak H (2004) High prevalence of thorn-shaped astrocytes in the aged human medial temporal lobe. Neurobiol Aging 25(3):397-405. https:// doi.org/10.1016/s0197-4580(03)00113-1

Sieracka J, Sieracki P, Kozera G, Szurowska E, Gulczyński J, Sobolewski P, Kloc W, Iżycka-Świeszewska E (2021) COVID19-neuropathological point of view, pathobiology, and dilemmas after the first year of the pandemic struggle. Folia Neuropathol 59(1):1-16. https://doi.org/10.5114/fn.2021.105128

Spencer PS, Mazumder R, Palmer VS, Lasarev MR, Stadnik RC, King P, Kabahenda M, Kitara DL, Stadler D, McArdle B, Tumwine JK (2016) Environmental, dietary and case-control study of Nodding Syndrome in Uganda: a post-measles brain disorder triggered by malnutrition? J Neurol Sci 369:191-203. https://doi.org/10.1016/j. jns.2016.08.023

Thal DR, Rüb U, Orantes M, Braak H (2002) Phases of A beta-deposition in the human brain and its relevance for the development of AD. Neurology 58(12):1791-1800. https://doi.org/10.1212/wnl. 58.12 .1791

Wang Q, Davis PB, Gurney ME, Xu R (2021) COVID-19 and dementia: Analyses of risk, disparity, and outcomes from electronic health records in the US. Alzheimers Dement. https://doi.org/10. 1002/alz.12296

Publisher's Note Springer Nature remains neutral with regard to jurisdictional claims in published maps and institutional affiliations. 